\title{
Limits of the current EU regulatory framework on GMOs: risk of not authorized GM event-traces in imports
}

Julie Roïz ${ }^{\star}$

FEDIOL, Avenue de Tervuren 168 (bte 2), 1150 Brussels, Belgium

Received 16 August 2014 - Accepted 15 September 2014

\begin{abstract}
Since their first commercialization in the 1990's, the number of genetically modified organisms (GMOs) cultivated around the world has steadily increased. This development has been accompanied by the development of regulatory and policy environments which vary from one country to another. Today, the European food and feed sectors are faced with the increasing risk of finding traces of not authorized GMOs in imports. Under the EU zero tolerance for unapproved GMOs, this situation may lead to trade disruptions with important cost implications. A regulatory environment which minimizes the risk of such disruption is therefore indispensable. To address this issue, the EU has adopted the "technical solution" but this remains insufficient to provide the necessary legal certainty which is needed to operate in such context. More comprehensive approaches are considered globally through low level presence policies.
\end{abstract}

Keywords: GMO / regulatory framework / EU / technical solution / low level presence policy

\begin{abstract}
Résumé - Limites de l'actuelle législation européenne relative aux OGMs : risque lié à la présence de traces de matériel génétiquement modifié non autorisé dans les importations. Depuis leur première commercialisation dans les années 1990, le nombre d'organismes génétiquement modifiés (OGMs) cultivés à travers le monde n'a cessé de progresser. Ce développement s'est accompagné de la mise en place d'environnements réglementaire et politique qui varient d'un pays à l'autre. Aujourd'hui, les secteurs européens de l'alimentation humaine et de l'alimentation animale sont confrontés au risque croissant de trouver des traces d'OGMs non-autorisés dans leurs importations. Dans le contexte européen de tolérance zéro vis-à-vis des OGMs non autorisés, cette situation peut aboutir à une rupture des approvisionnements avec des impacts économiques importants. Un environnement réglementaire qui minimise de tels risques est donc indispensable. Pour résoudre ce problème, l'Europe a adopté la « solution technique » mais cela reste insuffisant pour apporter la sécurité juridique nécessaire pour opérer dans un tel contexte. Des approches plus globales, de politiques sur la faible présence d'OGMs non autorisés, sont considérées à l'échelle mondiale.
\end{abstract}

Mots clés : OGM / réglementation / UE / solution technique / politique sur la faible présence d'OGMs non autorisés

\section{Introduction}

The cultivation of GMOs has grown rapidly around the world since they were first introduced in the 1990's. In 2013, the area cultivated with GM crops was estimated around 175 million hectares (James, 2013a). In some important exporting countries, and for some crops, the GMOs account

\footnotetext{
^ Correspondence: jroiz@fediol.eu
}

now for the main share of the total production (Brookes and Barfoot, 2014).

The commercialization of GMOs is a regulated activity and their approval is country-specific. As a consequence, some GMOs may be cultivated and commercialized in some countries but may not be (yet) approved for use in others.

In the European Union (EU), a zero tolerance policy is applied for non-authorized GMOs. GMOs have therefore to be approved under the EU regulatory system before entering 
the market. In practice, this means that any traded commodity which contains even traces of an EU unapproved GMO is considered non-compliant and must be withdrawn from the market, even if the European food safety authority (EFSA) has delivered a favorable opinion with regard to its safety.

Given the dependence of the EU on imports and as a consequence of the expansion of GMOs around the world, the probability to find trace amounts of unapproved GMOs which inadvertently find their way in the imported commodities is increasing, despite the precautions taken by the operators to keep them away (Stein and Rodriguez-Cerezo, 2010). When a zero tolerance is applied, this may lead to market disruptions with important cost implications (Kalaitzandonakes et al., 2014; Ryan and Smyth, 2012).

Solutions are therefore needed to prevent such disruptions and safeguard vital imports for the EU food and feed sectors.

This article provides an overview of the current EU regulatory system on GMOs. It describes the issue related to the presence of not authorized GMOs in supplies faced today by the EU food and feed business operators and the different factors contributing to such presence. It finally presents the instruments and policies envisaged today at EU and global level to minimize the risk of supply disruption in such context.

\section{The EU regulatory framework on GMOs}

\subsection{The authorisation system}

In the EU, a zero tolerance applies to non-EU authorized GMOs. Before they can enter the EU market, GMOs (and derived food and feed products) have to go through regulatory approval.

\subsection{Types of authorisation}

There are two main types of authorisation:

- Authorisation for the placing of GM food and feed on the market: this type of authorisation is governed by Regulation (EC) 1829/2003 (EC, 2003). Such authorisation applies for the following products:

- GMOs for food or feed use.

- Food or feed containing GMOs, produced from GMOs, or containing ingredients produced from GMOs.

- Authorisation for the deliberate release of GMO in the environment: this type of authorisation is governed by Directive 2001/18/EC (EC, 2001). The deliberate release corresponds to the introduction of the GMO into the environment without any precise confinement measure being taken to restrict the contact with the population or the environment. There are two categories of deliberate release of GMO into the environment:

- The experimental release: it corresponds to the introduction of the GMO into the environment for experimental purpose. Typical examples include field trials for the purpose of study, research, demonstration or development of novel varieties. This type of release is referred to in Part B of the Directive.
- The placing on the market for commercial purpose: it corresponds to the introduction of the GMO on the market for the purpose of cultivation, importation or transformation of GMOs into industrial products. Typical examples are import of GM flowers or GM seeds for cultivation. This type of release is referred to in Part C of the Directive.

Applications for cultivation can be submitted either under Directive 2001/18/EC (if the GMO has purely industrial uses and does not have food or feed application) or under Regulation (EC) $1829 / 2003$ (if the GMO is to be used in food or feed).

\subsection{Main steps of the authorisation process for GMOs to be placed on the market}

\subsubsection{Authorisation under Regulation (EC) 1829/2003}

The authorisation process for applications submitted under Regulation (EC) 1829/2003 involves three steps:

- Submission of the application: applicants submit their applications for authorisation to a Member State authority accompanied by the following supporting documents: studies showing the safety of the GM product in terms of human and animal health and environment, studies showing that the characteristics of the GM product are not different with respect to the conventional counterpart and reference varieties, a proposal for product labelling, detection and sampling methods, a sample material, a proposal for post-market monitoring regarding the use of the GM food or feed in human and animal consumption (and if relevant a proposal for monitoring environmental effects), and a summary of the application dossier. Regulation (EC) 641/2004 (EC, 2004) provides further details regarding the content of an application under Regulation (EC) 1829/2003, in particular regarding method validation and reference material. The Member State authority then submits the application to EFSA for the risk assessment. EFSA notifies without delay the other Member States and the Commission of the application and makes the application available to them. It also makes the application summary available to the public.

- Risk assessment: the objective of the risk assessment is to determine whether the applicant has adequately and sufficiently demonstrated that the GMO, and the foods and feeds derived thereof, are as safe and as nutritious as their conventional counterpart with respect to potential effects on human and animal health and the environment.

EFSA's Panel on GMO $^{1}$ starts its scientific assessment once the application is considered valid (i.e. that all required documents are present). EFSA has six months to formulate an opinion which includes the scientific risk assessment but also some suggestions regarding labelling, possible restrictions, or monitoring.

Regulation (EU) 503/2013 (EC, 2013a) sets out mandatory requirements regarding the data to be provided for the risk

1 The GMO Panel brings together highly qualified risk assessment experts from a number of European nationalities. 
assessment of GMO applications submitted under Regulation (EC) 1829/2003. This Regulation has transferred existing EFSA Guidance for risk assessment of GM foods and feeds into a legally binding document. Whilst the Regulation reflects largely the content of the EFSA guidance, several new elements have been added by the Member States and the European Commission, some of which representing significant differences with the existing EFSA recommendations (such as the mandatory requirement for the 90-day rodent feeding study for each single transformation events, irrespective of the quality of the available data provided for the risk assessment and case-by-case principle advocated by the EFSA GMO Panel) (Waigmann et al., 2013). Once EFSA publishes its risk assessment, the public has 30 days to comment on the Commission website.

- Risk management: the European Commission produces a draft decision to grant or refuse authorisation within 3 months of receiving the opinion of EFSA.

Under the examination procedure ${ }^{2}$, the draft decision is submitted by the European Commission to a regulatory committee of representatives of the Member States (the Standing Committee on the Food Chain and Animal Health or $\mathrm{SCoFCAH}^{3}$ ) for approval or rejection by a qualified majority vote (QMV).

- If the Committee delivers a negative opinion by QMV, the Commission cannot adopt the decision.

- If it gives a favourable opinion by QMV, the Commission shall adopt the decision.

- EU Member States are divided on the issue of GMO authorisations and usually offer a "no opinion" at the SCoFCAH. In such case, the Commission may resubmit the draft decision to the SCoFCAH but it usually submits the draft decision to the Appeal Committee ${ }^{4}$ (this has to be done within one month of the SCoFCAH decision). The Appeal Committee delivers Opinion by QMV. If the Appeal Committee gives no opinion, the Commission "may" adopt the decision. In such case, a final decision as regards the autorisation has therefore to be taken by the College of Commissioners. This is usually done by written procedure (but it may also be done through a vote during a College meeting $)^{5}$. Although there is no precise timeline within which such a final decision has to be made, the Commission is supposed to proceed without excessive delay.

\footnotetext{
2 Since 1 March 2011 and the new "comitology" Regulation (Regulation 182/2011/EU), the legislative procedure governing the authorisation process for GMO is the examination procedure.

3 SCoFCAH is made up of representatives from EU governments and public authorities. Its mandate covers the entire food supply chain - from animal health issues on the farm to the product on the consumer's table - helping the EU deal effectively with health risks any every stage of the production chain. It is chaired by a European Commission representative.

4 The Appeal Committee is composed of member state representatives, usually at senior level. It is chaired by the Commission and delivers opinions by qualified majority.

5 Commission Decision of 24 February 2010 amending its Rules of Procedure (2010/138/EU, Euratom).
}

Before 1 March 2011, under the regulatory procedure, should SCoFCAH not be able to reach a QMV, the Commission had to submit the draft decision to the EU Council of Ministers which had to achieve a QMV to adopt or oppose the draft decision. When the Council was not able to reach a QMV, the Commission was obliged to adopt the decision (Viju et al., 2011).

\subsubsection{Authorisation under Directive 2001/18/EC}

The authorisation process for applications submitted under Directive 2001/18/EC is different:

- Before a GMO or a combination of GMOs as or in products, is placed on the market, a notification has to be made to the competent authority of the Member State where the GMO is to be placed on the market for the first time. This notification contains: information required in Annexes III and IV of Directive 2001/18/EC, an environmental risk assessment with corresponding conclusions, the conditions for the placing on the market of the product (including specific conditions of use and handling), a proposed period for the consent which should not exceed ten years, a plan for monitoring regarding possible impact on the environment and on human health, a proposal for labelling and packaging and a summary of the dossier.

The national authority immediately forwards the summary of the dossier to the competent authorities of the other Member States and to the Commission.

- The national authority then prepares a scientific assessment report on the notification and sends the report to the Commission (which forwards it to the competent authorities of the other Member States) within 90 days. In case the report is unfavourable, the applicant may submit the same notification to another Member State authority.The public has 30 days to comment on the Joint Research Centre website on the assessment report of the "lead" national authority.

- If the assessment report provides a favourable opinion, and in absence of any objection from the other Member States or the Commission, the national authority that carried out the assessment report authorizes the placing of the product on the market. The authorized product may then be placed on the market throughout the EU as long as it meets with any condition contained in the authorization.

- If objections are raised, the procedure provides for a phase of discussion with the aim at arriving at an agreement within 105 days from the date of circulation of the assessment report. If after this period there is no agreement, a decision has to be taken at the European level and the Commission asks for the opinion of EFSA. The following steps are then similar to the management phase carried out for an application under Regulation (EC) $1829 / 2003$.

- A Commission proposal to amend Directive 2001/18/EC (EC, 2010) as regards cultivation is today under discussion (this point is further detailed below). 


\subsection{Authorisation process for stacked events}

Stacked events (or stacks) are GMOs with multiple events which have been combined by conventional crossing of GM plants with single events. These GMOs are developed to maximize the benefits of the individual traits into one single plant. In 2013, stacked events occupied an important part (27\%) of the global GM area and their development is today increasing (James, 2013b).

Under the EU legislation, stacked events are considered as new GMOs and are assessed in a similar way than single events, irrespective of whether the single events have already been authorized. In practice, this means that the single events have to be assessed prior to the assessment of the stack application. The risk assessment of stacked events also follows the provisions of Regulation (EU) 503/2013 (EC, 2013a) which stipulates that where all single events have been assessed, the risk assessment of stacked events should also be assessed in relation to: (i) stability of the inserts; (ii) expression of the introduced genes and their gene products; and (iii) potential synergistic or antagonistic effects resulting from the combination of the events.

\subsection{Restrictive measures at Member State level}

Although decisions as regards authorisations are taken at Community level, Member States have room to manoeuvre with the possibility to activate safeguard clause or emergency measure to ban GMOs on their territory. These restrictive measures can be taken by Member States, based on different legal bases:

- Safeguard clause: a Member State may invoke this restrictive measure, directly and at its own initiative, based on article 23 of Directive 2001/18/EC: "Where a Member State, as a result of new or additional information made available since the date of the consent and affecting the environmental risk assessment or reassessment of existing information on the basis of new or additional scientific knowledge, has detailed grounds for considering that a GMO as or in a product which has been properly notified and has received written consent under this Directive constitutes a risk to human health or the environment, that Member State may provisionally restrict or prohibit the use and/or sale of that GMO as or in a product on its territory."

- Emergency measure: a Member State may adopt this interim protective measure, only after the Commission has been officially informed by the Member State of the need to take emergency measures and where the Commission has not acted, based on article 34 of Regulation (EC) 1829/2003: "Where it is evident that products authorised by or in accordance with this Regulation are likely to constitute a serious risk to human health, animal health or the environment, or where, in the light of an opinion of the Authority issued under Article 10 or Article 22, the need to suspend or modify urgently an authorisation arises, measures shall be taken..." According to article 54 of Regulation 178/2002 "Where a Member State officially informs the Commission of the need to take emergency measures, and where the Commission has not acted in accordance with Article 53, the Member State may adopt interim protective measures. In this event, it shall immediately inform the other Member States and the Commission."

Currently, nine Member States (Austria, Bulgaria, Greece, Germany, Hungary, Italy, Luxembourg, Poland and France) (EC, 2013b; FR, 2014) have adopted such measures to prohibit the cultivation of the GM maize MON810 (the only GM event currently approved for cultivation ${ }^{6}$ ) on their territories. Most of the time, the scientific evidence provided by the Member States as a justification for their measure was found by EFSA to be insufficient. Nonetheless, in most cases, the EU has allowed the bans to continue (after the Council rejected several times Commission's proposals requesting Member States to repeal their national safeguard measures).

In July 2010, in response to this unsatisfactory situation, the Commission presented a legislative proposal (EC, 2010) amending Directive 2001/18/EC to grant Member States more flexibility to decide on GMO cultivation on their territories (cultivation opt-out), on grounds other than health and environment considerations. With such proposal, the aim of the Commission is to address specific national or local aspects raised by the cultivation issue but also to have an easier and more transparent decision-making in future GMO authorisation procedures. In 2011, the European Parliament broadly supported the concept of cultivation opt-out in its first vote, with a position that Member States should be able to cite social, economic but also environmental motives (where those factors have not been addressed as part of the EFSA environmental risk assessment) for doing so. But the proposal was blocked one year later at Council level as a blocking minority of delegations still had concerns regarding some issues (legal compatibility with WTO and EU internal market rules, move away from a "science-based" decision-making process with EFSA position being undermined). This prevented the Council to reach a political agreement. In March 2014, the Environment Council held a new public exchange of views on the Commission's proposal. This exchange took place just after the Council failed to find a qualified majority as regards the decision authorizing the placing on the market of the GM maize $1507^{7}$ obliging the Commission to authorize it for cultivation. In this context, most EU Environment ministers reacted favourably to the proposal to re-open discussion as regards the Commission cultivation proposal. In June 2014, the Environment Council finally reached a political agreement. This was followed by the adoption of the Council first-reading position in July 2014 (Council of the EU, 2014) which allows talks to begin with MEPs in 2nd reading.

\footnotetext{
${ }^{6}$ In December 2013, the European Court annulled the cultivation authorisation of the Amflora potato which was the only other GMO that had been approved for cultivation in Europe.

7 This was following a vote of the Regulatory Committee on a draft authorisation proposal presented by the Commission in February 2009 which could not deliver an opinion and a judgment of the General Court of the EU that the Commission had failed to submit without delay a proposal to the Council (according to the applicable old comitology rules at that time).
} 


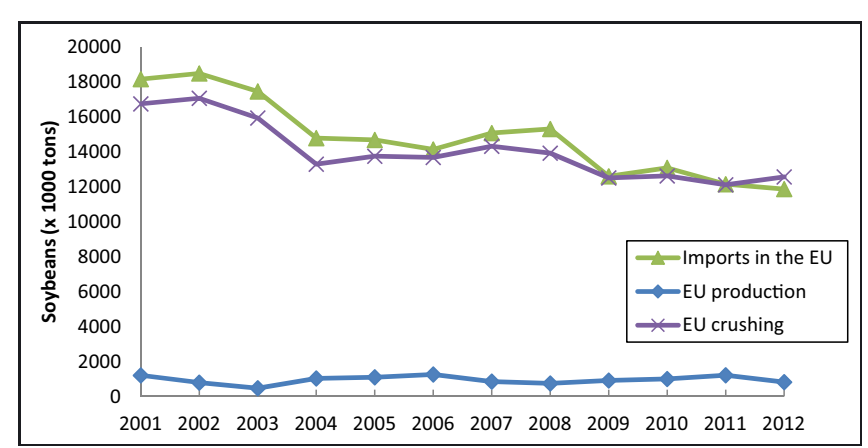

Fig. 1. Role of import for the soybean processed in the EU (Source: FEDIOL, 2013).

\subsection{Labelling}

Food and feed products consisting of GMOs, containing GMOs or produced from GMOs which are authorised under Regulation (EC) 1829/2003 or under Directive 2001/18/EC (Part C) are subject to the mandatory GM labelling requirements laid down in Regulation (EC) 1829/2003 and in Regulation (EC) 1830/2003. According to Regulation (EC) $1829 / 2003$, additional labelling is required when the food or the feed is different from its conventional counterpart or when it may give rise to ethical or religious concerns. The legislation does not require labelling of products which contain traces of authorized GMOs no higher than $0.9 \%$, provided this GM presence is adventitious and technically unavoidable. Products derived from GMOs have to be labeled irrespective of whether the genetic modification is still detectable in the final product. Highly refined products such as refined vegetable oils have therefore to be labelled.

\section{Increasing risk to find traces of not authorized GMOs in imports and regulatory instruments to safeguard trade}

\subsection{Increasing probability to find traces of not (yet) authorized GM events in imports}

The European Union is not self-sufficient in relation to food and feed production and has to rely on imports to cover the industry demand. Imports are a vital complement to the EU raw material supply.

Putting forward the example of soybeans, the EU production covers only $7 \%$ of the soybean processed in EU with little fluctuation for the past 10 years (see Fig. 1). The increase in EU production is limited due to agronomic and climatic reasons and cannot replace imports.

Though critical for the European market, imports remain under constant threat caused by a possible presence of traces of GM events that (1) have not yet been authorized in the EU (but have already been safety assessed and authorized in the exporting countries) or (2) by traces of GM events that are not intended to be approved in the EU market. Such presence is unintentional and despite all efforts technically unavoidable.
Based on data collected from 75 out of its 193 member countries, the Food and Agriculture Organization of the United Nations (FAO) reported that the detection and identification of traces of unauthorized GMOs, found in food and feed shipments have increased over the last ten years (FAO, 2014). 198 incidents related to traces of unauthorized GMOs into supplies have been reported between 2002 and 2012 with a significant increase since 2009 (when 138 incidents were reported). According to the FAO survey, the major commodities which have been associated so far with GM trace incidents are linseed, rice and maize and the shipments involved have originated mainly from the US, Canada and China.

Although the number of incidents reported by FAO is relatively small in relation to the quantities of food and feed traded every day around the world, their occurrence is reported to increase. In the current EU regulatory context (zero tolerance policy and feed only technical solution), the food and feed sectors are therefore increasingly exposed to the risk of trade disruptions which can result from such incidents and of which the cost may be considerable (Brookes, 2008; Kalaitzandonakes et al., 2013).

Different factors, detailed in the paragraphs below, contribute to the increasing risk to find traces of not (yet) authorized GM events in imports.

\subsection{Increasing area and number of GM cultivated worldwide}

The area of GM crops cultivated around the world has increased from 1.7 million hectares in 1996, to over 175 million hectares in 2013 (James, 2013a). The five largest GM producers in terms of surface area are the US (70.1 million hectares) followed by Brazil (40.3 million hectares), Argentina (24.4 million hectares), India (11.0 million hectares) and Canada (10.8 million hectares) (James, 2013b). In some important exporting countries, and for some crops, the GMOs account now for the main share of the total production. For soybean, in 2012, the GM adoption rate was estimated to be around $93 \%$ in the US, $89 \%$ in Brazil, and 99\% in Argentina. For canola, in 2012, the GM adoption rate was estimated to be around $97 \%$ in the US, 98\% in Canada and 7\% in Australia (Brookes and Barfoot, 2014). With this increasing area of land under cultivation with GMOs, sourcing strategy to avoid the presence of minute traces of not EU authorized GMOs, is becoming more and more complicated.

\subsection{Asynchronous authorisations}

The EU regulatory procedure for approving GMOs takes a significantly longer time than in exporting countries. The EU takes 48 months on average for an import approval compared to 30 months on average in the big supplier countries (Canada, US, Argentina, Brazil) (EuropaBio, 2014). Several factors are advanced to explain this longer average duration of the authorisation process:

- At the risk assessment stage: factors include the fast changing data requirements and their retroactive application, the communication between EFSA and the applicants, the 
way additional information is handled and managed, and the risk assessment of stack applications which requires the completion of the assessment of the respective single events (EuropaBio, 2011). In 2013, stacked events occupied an important part (27\%) of the global GM area. The trend towards more stacks is expected to grow (James, 2013b) which is raising concerns as regards the ability of the current EU approval process to cope with the increasing number of stacks available on the market.

- At the risk management phase: factors include the delay of the Commission in presenting an EFSA opinion to the SCoFCAH over the three-month deadline ${ }^{8}$, the excessive delay (even if there is no legal timeline for it) and the politicization of the final stage of the approval after the two rounds of voting by Member States (EuropaBio, 2014).

The differences in the speed of authorization continue to lead to situations where products are approved for commercial use outside the EU but not within the EU (asynchronous approvals).

\subsection{Asymmetric authorisations}

This situation occurs when the producing country approves a GMO but does not submit an application for the approval in the country where the GMO trace is found. This GM crop may nevertheless find its way into international supply chains in other parts of the world, e.g. by carry-over, and may lead to trace occurrences in batches from this country.

In 2009, trace amounts of a GM flaxseed (FP967) were found in some Canadian flaxseed shipments. FP967 had received Canadian and US regulatory feed and environmental safety authorizations in the 1990's, but the variety was ultimately not commercialized and no application had been submitted for EU approval. This incident triggered a market standstill (as the alternative available quantities for export from countries other than Canada could not fill the gap of the volumes lost in Europe) which caused significant economic losses for the European linseed market and stakeholders (Ryan and Smyth, 2012).

\subsection{Discontinued events}

This situation may occur when the approval of the GMO expires in the importing countries and when no application is submitted for the continuation of the approval.

\subsection{Other factors}

Additional factors may contribute to the occurrence of traces of not (yet) approved GMOs (FAO, 2014):

- Lack of clear field trial policies and protocols.

- Carry-over during storage or transport in an increasingly complex logistic network.

${ }^{8}$ See the answer given by Mr Dalli on behalf of the Commission on 22 June 2012 to the parliamentary question E-004184, recognizing that the Commission is regularly failing to submit EFSA opinion to the SCoFCAH within the three month prescribed deadline.
- Inspection regimes: the frequency of inspections to detect traces of not (yet) authorized GMOs may vary among the countries.

\subsection{Regulatory instruments and policies to safeguard trade}

\subsubsection{Technical Solution}

In May 2008, in the context of an orientation debate on GMOs, the EU College of Commissioners instructed its services to find a "technical solution" to the issue of minute traces of not authorized GMOs in feed and foodstuffs "as soon as possible and at the latest before the summer".

One year later (in August and September 2009), several shipments of US soybean and soybean meal were found to contain minute traces of GM maize events (MON88017 and MIR164) that were approved in the US but not in the EU (Landmark Europe, 2009). In total, hundreds of thousands of tons of soybean and soybean meal were denied entry into the EU because of this issue. This resulted in significant implications for EU food and feed operators (who had to stop imports for soybeans and soybean meals from the US while at the same time facing higher prices of soybean on the market). Fortunately, however, the detected GM events had already been safety assessed by EFSA and the Commission could speed up their authorization process (they were approved in October ${ }^{9}$ and November ${ }^{10}$ 2009) which allowed mitigating further crises.

This situation prompted the European Commission to propose a technical solution providing a definition of what should be considered zero as regards not yet authorized GMOs in imports, while maintaining the EU position on zero tolerance. Regulation 619/2011 (the so-called "technical solution" for feed) (EC, 2011) was adopted in October 2011. It introduced harmonized rules for testing with the definition of methods for sampling and for analysis. It also set the "technical zero" at $0.1 \%$ (mass fraction of GM material in the tested material) at which results can be interpreted robustly. This technical solution is limited to feed materials. It applies to GMOs authorized for commercialization in a non-EU country and for which a valid EFSA application has been submitted (and for which an authorisation procedure has been pending for at least three months) or for which the authorization has expired.

The partial scope of the technical solution is today leaving the EU food sector increasingly exposed to serious legal uncertainty with the risk of disruption for the whole food supply

\footnotetext{
${ }^{9}$ Commission decision of 30 October 2009 authorising the placing on the market of products containing, consisting of, or produced from genetically modified maize MON 88017 (MON-88Ø17-3) pursuant to Regulation (EC) No. 1829/2003 of the European Parliament and of the Council.

10 Commission decision of 30 November 2009 authorising the placing on the market of products containing, consisting of, or produced from genetically modified maize MIR604 (SYN-IR6Ø4-5) pursuant to Regulation (EC) No. 1829/2003 of the European Parliament and of the Council.
} 
chain. The feed-only technical solution does not take into account the reality of the supply chains where many crops are used for both food and feed applications. In absence of a technical solution for food, any positive test result below $0.1 \%$ for not yet authorized GMO in a material destined for food will be considered as non compliant even if the statistical confidence associated with the result at this level is not satisfactory. In other words, a same result below $0.1 \%$ may lead to different conclusions as regards the compliance of an imported material depending on its final use (food or feed).

In this context, different EU stakeholders have provided data and called the European Commission to urge a technical solution for food. In 2013, the Commission decided to go through a formal impact assessment to evaluate the need to extend the scope of the technical solution to food and has opted for an external report to support the impact assessment (André, 2014).

\subsubsection{Low Level Presence (LLP) policy}

The issue of GM occurrence in imports is likely to get worse. Key exporting countries continue to adopt new GM crops and it is not clear whether they will continue efforts to adapt trade to the requirements of the EU in a context where significant importing markets (like Asia) have opened and where the EU has lost relative importance as a trading partner.

The so-called technical solution is meant to bridge the gap until EU authorisation. Although it can provide a short relief to asynchronous authorizations, the technical solution does not provide a lasting and workable solution to the low level presence of all sorts of not EU authorized GM events (asymmetric, research escaped...).

This situation has therefore pushed countries at international level to discuss possible LLP policies ${ }^{11}$. In Europe, although the issue of GM occurrence had been recognized at one time $^{12}$, the sensitive political context around GMOs in Europe has prevented the EU to take an active part in these discussions.

Some countries have already proposed LLP policies. In 2012, the Canadian Government drafted a proposed domestic policy on the management of low level presence of GM crops in imports (Heminthavong, 2013). This proposal provides for two action levels: (1) an action level of $0.1 \%$ or $0.2 \%$ for unapproved events which have been approved following a risk assessment consistent with the Codex guidelines and (2) threshold levels (varying by crop) which would be higher

\footnotetext{
11 The global LLP initiative brings together members (Argentina, Australia, Brazil, Canada, Chile, Costa Rica, Mexico, Paraguay, Philippines, Russia, United States, South Africa, Uruguay, Viet Nam) and observers (China, Colombia, Korea, EU). Three meetings have been organized so far by the global LLP initiative (Vancouver 2012, Rosario 2012, Durban 2013).

12 Article 47 of Regulation (EC) 1829/2003 provided for a transitional period of 3 years (from 2003 to 2006) during which, under certain conditions, the presence of an unapproved GMO in food or feed was not considered as in breach of the Regulation, if the presence of such GMO was not higher than $0.5 \%$.
}

than the action level threshold and that would set the maximum concentration of GM ingredients considered to be LLP. A presence below this threshold would not trigger any action. In Switzerland, the Federal Department of Home Affairs Ordinance on Genetically Modified Food (VGVL; SR 817.022.51, article 6 a) introduces a threshold of $0.5 \%$ for unauthorized GM material provided that they are authorized in another country where they have been assessed following comparable procedures. In the US, no threshold is set but a case-by-case approach based on safety and legal requirements is taken by the regulatory agencies in case a not authorized GMO is detected (FAO, 2014).

\section{Conclusion}

Incidents related to traces of not authorized GM material into imports have occurred in the past. So far, the EU food and feed business operators have been trying to secure their supplies by minimizing the risks involved with the trading of commodities. But with the increased planting and harvesting of GMOs around the world, the probability of having a nonauthorized event showing up in supplies is going to intensify, despite the precautions taken.

In this context, the current EU regulatory framework does not provide the legal certainty which is necessary for the EU food and feed sectors to operate. The absence of technical solution for food leaves the food operators increasingly exposed to face enormous financial losses due to non compliant shipments.

While countries around the world discuss and consider how to address low level presence of unapproved GMOs with practical solution in a view to maintain sourcing of raw materials, the political sensitivity of the GM issue in the EU is preventing non-emotional analysis and search for solution to anticipate trade disruptions.

\section{References}

André D. 2014. LLP policy in the EU implementation and implications. Presentation given in: FAO technical consultation on low levels of genetically modified (GM) crops in international food and feed trade. Rome, 20-21 March 2014. Available from: http://www.fao.org/fileadmin/user_upload/agns/topics/ LLP/Presentations/11_EU_Final.pdf.

Brookes, G. 2008. Economic impacts of low level presence of not yet approved GMOs on the EU food sector (Report commissioned by European trade and industry organizations). Gloucester, UK: Graham Brookes Consulting. Available from: http://www. agrodigital.com/images/estudio.pdf.

Brookes G, Barfoot P. 2014. GM crops: global socio-economic and environmental Impacts 1996-2012. PG Economics Ltd, UK.

Council of the EU. 2014. Position of the Council at first reading with a view to the adoption of a directive of the European Parliament and of the Council amending Directive 2001/18/EC as regards the possibility for the Member States to restrict or prohibit the cultivation of genetically modified organisms (GMOs) in their territory. Available from: http://register.consilium.europa.eu/doc/srv? $1=\mathrm{EN} \backslash \& \mathrm{f}=\mathrm{ST} \% 2010972 \% 202014 \% 20$ INIT . 
European Commission. 2001. Directive 2001/18/EC of the European Parliament and of the Council of 12 March 2001 on the deliberate release into the environment of genetically modified organisms and repealing Council Directive 90/220/EEC. Brussels: Official Journal of the European Communities. Available from: http://eur-lex.europa.eu/legal-content/EN/TXT/? uri=CELEX:32001L0018.

European Commission. 2003. Regulation (EC) No 1829/2003 of the European Parliament and of the Council of 22 September 2003 on genetically modified food and feed. Brussels: Official Journal of the European Communities. Available from: http://eur-lex. europa.eu/legal-content/en/ALL/?uri=CELEX:32003R1829.

European Commission. 2004. Commission Regulation (EC) No 641/2004 of 6 April 2004 on detailed rules for the implementation of Regulation (EC) No 1829/2003 of the European Parliament and of the Council as regards the application for the authorisation of new genetically modified food and feed, the notification of existing products and adventitious or technically unavoidable presence of genetically modified material which has benefited from a favourable risk evaluation. Brussels: Official Journal of the European Communities. Available from: http://eur-lex.europa.eu/legal-content/EN/TXT/? uri=CELEX\%3A02004R0641-20130628 \\&qid=1404219033271

European Commission. 2010. Proposal for a regulation of the European Parliament and of the Council amending Directive 2001/18/EC as regards the possibility for the Member States to restrict or prohibit the cultivation of GMOs in their territory $\operatorname{COM}(2010) 380$ final.

European Commission. 2011. Commission Regulation (EU) No 619/2011 of 24 June 2011 laying down the methods of sampling and analysis for the official control of feed as regards presence of genetically modified material for which an authorization procedure is pending or the authorisation of which has expired. Brussels: Official Journal of the European Communities. Available from: http://eur-lex.europa.eu/legal-content/EN/TXT/? uri=CELEX\%3A32011R0619 \\&qid=1404383414652.

European Commission. 2013a. Commission Implementing Regulation (EU) No 503/2013 of 3 April 2013 on applications for authorisation of genetically modified food and feed in accordance with Regulation (EC) No 1829/2003 of the European Parliament and of the Council and amending Commission Regulations (EC) No 641/2004 and (EC) No 1981/2006. Brussels: Official Journal of the European Communities. Available from: http://eur-lex. europa.eu/legal-content/EN/TXT/?uri=OJ:L:2013:157:TOC

European Commission. 2013b. MEMO/13/952 - Questions and Answers on EU's policies on cultivation and imports of GMOs. Available from: http://europa.eu/rapid/press-release MEMO-13-952_en.htm.
EuropaBio. 2011. Approvals of GMOs in the European Union. Available from: http://www.europabio.org/ approvals-gmos-european-union.

EuropaBio, 2014. Undue delays in EU authorization of safe GM crops. Available from: http://www.europabio.org/positions/ undue-delays-eu-authorisation-safe-gm-crops.

FAO. 2014. Technical consultation on low levels of genetically modified (GM) crops in international food and feed trade - Technical background paper 1 - Low levels of GM crops in food and feed: regulatory issues. Available from: http://www.fao.org/food/ food-safety-quality/a-z-index/biotechnology/llp/en/

FEDIOL. 2013. FEDIOL statistics: oilseeds production, imports, exports and crushing- Evolution 1980-2012. Available from: http:// www.fediol.org/web/statistics/1011306087/list1187970187/f1. html.

France 2014. Loi No. 2014-567 du 3 juin 2014 relative à l'interdiction de la mise en culture des variétés de maïs génétiquement modifié. Paris: Journal Officiel de la République Française. Available from: http://www.legifrance.gouv.fr/affichTexte.do?cidTexte=JORFTEXT000029035842\&dateTexte $=$ \&categorieLien=id.

Heminthavong K. 2013. Low-level presence of genetically modified crops in imports: proposed domestic policy (In Brief). Library of Parliament, Ottawa, Canada.

James C. 2013a. Top 5 facts about biotech/gm crops in 2013.

James C. 2013b. Global status of commercialized biotech/GM crops: 2013.

Kalaitzandonakes N., Kaufman J., Miller D. 2014. Potential economic impacts of zero thresholds for unapproved GMOs: The EU case. Food Policy 45: 146-157.

Landmark Europe. 2009. The cost of low level presence of GMOs in food products in Europe. An impact assessment based on the recent RASFF 2009.1037 \& 2009.1165.

Ryan C.D. and Smyth S.J. 2012. Economic Implications of Low Level Presence in a Zero Tolerance European Import Market: The Case of Canadian Triffid Flax. AgBioForum.15: 21-30

Stein A.J., Rodríguez-Cerezo E. 2010. Low-level presence of new GM crops: an issue on the rise for countries where they lack approval. AgBioForum 13: 173-182.

Viju C., Yeung M.T. and Kerr W. 2011. Post-Moratorium EU Regulation of Genetically Modified Products: Trade Concerns, CATPRN Commissioned Paper. Available from: http:// ageconsearch.umn.edu/bitstream/116848/2/CP-2011-02-Viju. pdf.

Waigmann E., Gomes A., Lanzoni A., Perry J.N. 2013. Editorial: New Commission Implementing Regulation on Risk Assessment of GM plant applications: novel elements and challenges. EFSA J. 11: e11121. 